\title{
Effects of Education Concerning Radiation and Nuclear Safety and Regulation on Elementary, Middle, and High School Students in Korea
}

\author{
Yoon-Seok Choi', Jung-Min Kim', Eun-Ok Han² \\ ${ }^{1}$ Department of Bio-convergence Engineering, Korea University, Seoul, Korea; ${ }^{2}$ Department of Education \& Research, Korea Academy of Nuclear Safety, Seoul, \\ Korea
}

\section{Original Research}

Received February 6, 2020

Revision March 3, 2020

Accepted July 14, 2020

Corresponding author: Eun-Ok Han

Department of Education \& Research, Korea Academy of Nuclear Safety, 260 Songpa-daero, Songpa-gu,

Seoul 05719, Korea

E-mail: haneunok@gmail.com

(iD) https://orcid.org/0000-0001-8670-2633

This is an open-access article distributed under the terms of the Creative Commons Attribution License (http://creativecommons.org/licenses/by-nc/4.0), which permits unrestricted use, distribution, and reproduction in any medium, provided the original work is properly cited.

Copyright $\odot 2020$ The Korean Association for Radiation Protection

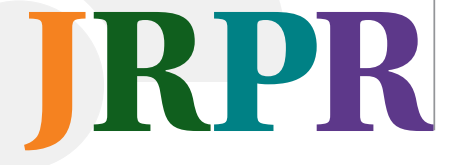

Background: This foundational study on educational interventions aimed to analyze the changes in awareness, knowledge, and attitudes of young learners after they received objective information on safety management.

Materials and Methods: Educational sessions on nuclear power and radiation safety were delivered to 4,934 Korean elementary, middle, and high school students in two separate sessions conducted in 2016 and 2017. The effects of these interventions were subsequently analyzed.

Results and Discussion: Learner attitudes toward safety were found to be the predominant variables affecting the post-intervention risk (safety) awareness of nuclear power generation.

Conclusion: The safety awareness of future generations will significantly influence policy decisions on nuclear power generation. Hence, the design of educational interventions on this subject must match variables suited to learner levels.

Keywords: Safety, Education, Radiation, Nuclear, School Students

\section{Introduction}

For South Korea, it is crucial to expand nuclear power and utilize radiation as an energy source in accordance with the Climate Change Convention, energy security concerns, and overall national welfare. Despite the politico-economic importance and the socio-cultural ripple effect which surrounds nuclear power, insufficient public communication and awareness has led to extreme levels of conflict and misunderstandings. Furthermore, awareness and attitudes toward nuclear power being discussed are not limited to vague fears, evolving into complaints, anxiety, and uncertainties about nuclear power policies [1]. Since the nuclear power plant accident in Fukushima, Japan, negative public awareness has further increased [2-6]. The risk awareness regarding nuclear energy is characterized by insufficient coordination after cognitive anchoring and accidental fixation by strong and negative images such as those from the Fukushima nuclear power plant accident, and the public risk awareness regarding nuclear technology and facilities is more affected $[7,8]$. Studies have shown that public awareness and acceptance of nuclear risks are influenced more politically and emotionally than by scientific and technical assessments [9]. Despite the importance of citizen awareness and attitude in the promotion and decision-making process connected to 
nuclear policy, negative media reports on the safety of nuclear power generation in South Korea and numerous undesirable media practices have led to a serious loss of confidence in the safety of nuclear power generation. Thus, a sufficient and reliable information and communication system is more urgent than the actual safety of nuclear power on various analyses and remedies on the various signs of nuclear power-plant risks. Furthermore, the system and efforts of media reports rendering knowledge on the safety of nuclear power generation needs to be more accessible to citizens. If nongovernmental organizations do not receive enough information, they could contribute to the creation of a vaguely negative image on the operation and accidents with regards to nuclear power plants, with no concrete grounds, which can lead to opposition with regards to the construction and operation of nuclear power plants [10, 11]. Such extreme conflicts over nuclear power in South Korea have been ultimately reflected in nuclear policy decisions. The need for safety education for elementary, middle, and high school students vulnerable to disasters has been recognized after experiencing the Fukushima nuclear power plant accident, due to the Great East Japan Earthquake in 2011, and the 304 deaths which occurred upon the Sinking of MV Sewol in South Korea in 2014. Particularly, because students have had little chance to learn about nuclear power and radiation during the formal education process, most of the information on this topic is likely to be obtained through media reports and rumors after the Fukushima nuclear accident. Consequently, students are in a situation prone to chaos due to groundless anxiety and being subjected to massive amounts of unfiltered negative information [12]. In summary, nuclear policy has faced various challenges not only in terms of policy, consumers' understanding, consensus, acceptance, and satisfaction, but also in terms of valued judgments for future generations. The development of science and technology, such as nuclear power generation, can lead to various social and ethical issues (socio-scientific issues) for general citizens. In this regard, science education researchers have emphasized the development of the ability to accurately evaluate and rationally cope with various socio-scientific issues based on the understanding of science and technology [13-16]. Due to the fact that, adults have difficulties in perceiving change through education, separate policy intervention is required. Furthermore, before failures in securing social acceptance are realized, due to the ignorance of nuclear power and radiation which continues to lead to erroneous political influ- ences, proper education should facilitate the inculcation of proper value judgments for future generations by providing accurate information and education at educational institutes. Hence, this study is aimed at inculcating proper value judgments to elementary, middle, and high school students by providing these students, which the ripple effect of communication and education would be the highest among the general public, with information on safety management regarding nuclear power generation and radiation, as well as governmental safety regulations. As a foundational study for educational intervention, this study is further aimed at analyzing changes in awareness, knowledge, and the attitudes of future generations in providing objective information on safety and safety management. The aforementioned is the primary reason for opposition regarding the acceptance of nuclear power generation and radiation within educational programs, and proposals related to an intervention strategy.

\section{Materials and Methods}

The educational design was based on the data developed by Han and her colleagues $[17,18]$. Furthermore, after the Fukushima nuclear power plant accident, a change in education policy in Japan was considered. Idate Village (飯館村), where all the residents were evacuated due to the accident at the Fukushima nuclear power plant, set up the goal that "people should be able to accurately understand radiation properties and their dangers, and to have basic knowledge to ensure a safe life for a lifetime as well as appropriate actions" to ease the extreme anxiety and to develop the abilities of children to cope with and respond to low radiation doses throughout their lifetime in relation to the evacuation area, village decontamination area, and surrounding village [12]. Furthermore, although the lack of understanding on radiation increased anxiety levels, which was pointed out immediately after the accident, unilaterally injecting knowledge into the minds of residents cannot solve the problem. Thus, this study was designed considering that interest was heightened through direct experiences, such as radiation measurement and related activities, in an attempt to deepen various understandings [19]. As an educational method, theoretical classes, such as discussion and student presentations, were held in the classroom for one hour after the lectures by the experts and the science teachers, and in the practice, a radiation dose detector was used at various places in the school and natural radiation measurement was performed for one 
hour. The contents of the lectures covered the safety management of nuclear power generation and radiation, governmental safety regulations for nuclear power generation, accidents, and responses to nuclear power plant disasters. All lectures lasted 2 hours and the content was the same in elementary, middle, and high schools. The education program implementation and survey were divided into 2016 and 2017. The first was from June to December 2016, and the second was from June to December 2017. The subjects were 4,934 elementary, middle, and high school students from 100 Korean schools. The questionnaire consisted of six questions regarding attitudes about using radiation, four questions about the experience of using radiation, four questions about the pros and cons of nuclear energy, five questions regarding recognition (necessity, safety, interest, information acquisition, knowledge), 17 questions based on objective knowledge, and three questions concerning general personal characteristics. The objective knowledge consisted of general knowledge of radiation and nuclear power $(\mathrm{Q} 1$. Radiation is everywhere in the sun, at the playground, in the classroom; Q2. Korea is operating nuclear power plants; Q3. Nuclear power is a method of energy production; Q4. Residents near nuclear power plants receive more radiation exposure than other regions; Q5. The United States, Canada, France, and Germany operate nuclear power plants), medical radiation (Q6. Radiation used in hospitals is not dangerous; Q7. The radiation used for diagnosis and cancer treatment is harmless to the human body; Q8. Radiation doses received from medical devices in hospitals are lower than those received from nuclear power plants; Q9. Radiation is used in hospitals to diagnose and treat illness; Q10. In developed countries, radiation is also used to diagnose and treat illness), radiation in irradiated food (Q11. Irradiated food is contaminated with radioactive materials; Q12. Irradiated foods emit radiation from food; Q13. Irradiation is a method of food storage and part of processing technology; Q14. Radiation is permitted for Korean red pepper paste, miso, and soy sauce powder; Q15. Internationally, potatoes and wheat and wheat are allowed to be irradiated), and safety regulation (Q16. Radiation users and nuclear power plants are managed by the government; Q17. Artificial radiation cannot be used anywhere without government permission). The survey was conducted before and after education, respectively. Male student participants were 1,404 (53.1\%) in 2016, and 1,134 (49.5\%) in 2017, and female student participants were 1,241 (46.9\%) in 2016 and 1,155 (50.5\%) in 2017. Students who had previously received train-
Table 1. Survey Subjects

\begin{tabular}{lcr}
\hline Item & 2016 & 2017 a) \\
\hline Gender & & \\
Men & $1,404(53.1)$ & $1,134(49.5)$ \\
Women & $1,241(46.9)$ & $1,155(50.5)$ \\
$\quad$ Total & $2,645(100)$ & $2,289(100)$ \\
Experience and education regarding & & \\
$\quad$ nuclear power and radiation & & \\
Yes & $258(9.8)$ & $288(12.6)$ \\
No & $1,966(74.9)$ & $1,625(71.3)$ \\
Do not know & $400(15.2)$ & $366(16.1)$ \\
Total & $2,624(100)$ & $2,279(100)$ \\
\hline
\end{tabular}

Values are presented as number of students with percentage in parentheses.

a) Year 2017 was the period that denuclearization policy was truly realized in Korea. This research was conducted to analyze the effects that will appear in educational sites before and after societal changes regarding viewpoints regarding nuclear policy were evident. A mock voting was performed regarding nuclear power plant construction in South Korea before and after education on the topic. The results were based on decisions by the students using their own discretion, and the students who voted against the construction provided the reasons for the opposition. The categories included "Dangerous", "Inappropriate to South Korea", "Not preferring nuclear power generation", "Unnecessary", and "Others". Despite the opposition among most expert groups, South Korea has suddenly moved away from the nuclear power plant expansion policy into nuclear power plant reduction policy, facing huge economic losses and energy security threats. This confusion could be explained by Girondi [20] and Eiser and van der Pligt [21] assertion that because the energy problem is a complexity involving social, political, and technological factors, the public support in social and political terms together with basic problems is an important factor in solving the energy problem. For South Korea, which must continuously use nuclear energy for national energy security and economic growth, it has become most important to promote the social acceptability of nuclear power [22]

ing on nuclear power or radiation consisted of $258(9.8 \%)$ in 2016, and 288 (12.6\%) in 2017, which were much fewer than the students who had no educational experience, consisting of 1,966 (74.9\%) in 2016, and 1,625 (71.3\%) in 2017 (Table 1). The questionnaire, based on the traditional learning model, consisted of awareness, knowledge, and attitude concerning nuclear power generation and radiation safety, and the three categories of radiation usage were nuclear power generation, medical radiation, and irradiated food. Statistical analysis was performed by using SPSS version 15 for Window (SPSS Inc., Chicago, IL, USA) for frequency and percentage, mean and standard deviation, t-test, and regression analysis.

\section{Results and Discussion}

\section{Educational Effect Concerning Nuclear Power Generation and Radiation Safety and Regulations by School Level}

The knowledge and attitude levels regarding nuclear pow- 


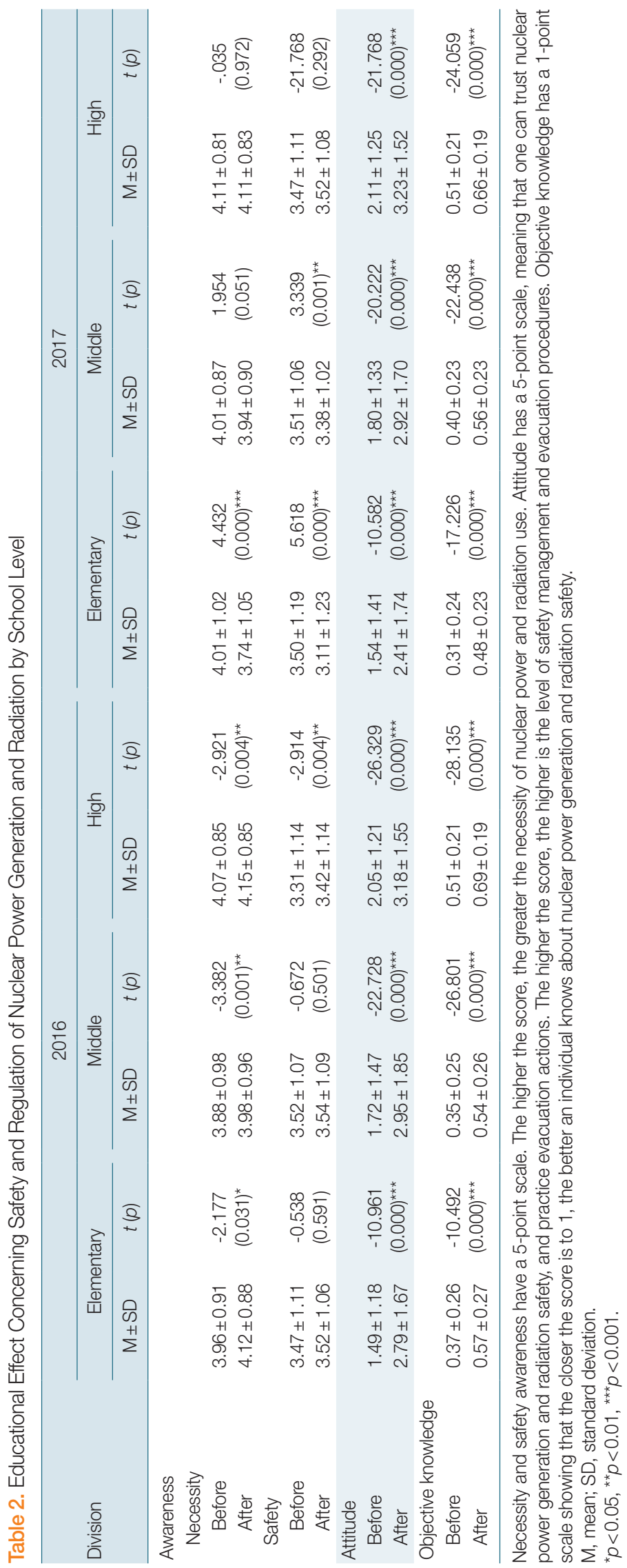

er generation and radiation safety in 2016 and 2017 were significantly higher following educational awareness compared to before educational awareness. However, in 2017, the level of awareness on safety was lower in elementary and middle school students after education. Awareness regarding the need for nuclear power generation and radiation changed upward in 2016, while declining in 2017 (Table 2). Although it is difficult to find the causes of objective relevance within the same educational program, which shows the opposite results on the changes in awareness between 2016 and 2017, media reports and political influence concerning the new President's Declaration of Denuclearization in the first half of 2017, could have influenced the students. In this regard, it can be interpreted that the adverse effect of education with regards to safety awareness suggests that students are strongly influenced more by the social environment than by the educational environment. This observation can be explained by the theory that the problem related to human awareness is subject to the collective culture of the society as a whole, or its organizational properties [23]. Experts perceive risk through technical rationale based on statistical data, while the public perceives risk by subjective judgment, such as an individual subjective experience, knowledge, or habits [24, 25]. According to Sjoberg [26], experts perceive the risks of science and technology as trivial, while the risk level is much higher in public perception. Thus, communication strategies based on public awareness patterns and pedagogical understanding, should be provided in classroom instructions.

\section{Educational Effect Concerning Safety and Regulation of Nuclear Power Generation and Radiation by Gender}

In 2016 and 2017, male students before and after the educational influence showed a higher level of awareness than female students regarding the need for nuclear power generation and radiation use, safety awareness, objective knowledge, and safety attitudes. There could be differences between male and female emotions in socio-economic circumstances in each country. Female students in South Korea showed a lower level of awareness, knowledge, and attitude about nuclear power than those of male students, which suggests that the education should be designed to consider gender differences, and further in-depth studies on the mechanism of the difference are necessary (Table 3 ). 
Table 3. Educational Effect Concerning Safety and Regulation of Nuclear Power Generation and Radiation by Gender

\begin{tabular}{|c|c|c|c|c|c|c|c|c|}
\hline \multirow{3}{*}{ Division } & \multicolumn{4}{|c|}{2016} & \multicolumn{4}{|c|}{2017} \\
\hline & \multicolumn{2}{|c|}{ Before education } & \multicolumn{2}{|c|}{ After education } & \multicolumn{2}{|c|}{ Before education } & \multicolumn{2}{|c|}{ After education } \\
\hline & $\mathrm{M} \pm \mathrm{SD}$ & $t(p)$ & $\mathrm{M} \pm \mathrm{SD}$ & $t(p)$ & $\mathrm{M} \pm \mathrm{SD}$ & $t(p)$ & $\mathrm{M} \pm \mathrm{SD}$ & $t(p)$ \\
\hline \multicolumn{9}{|l|}{ Awareness } \\
\hline \multicolumn{9}{|l|}{ Necessity } \\
\hline Male & $4.04 \pm 0.97$ & $3.579(0.000)^{\star \star \star}$ & $4.21 \pm 0.90$ & $8.814(0.000)^{\star \star \star}$ & $4.13 \pm 0.91$ & $4.226(0.000)^{\star \star \star}$ & $4.10 \pm 0.94$ & $6.863(0.000)^{\star \star \star}$ \\
\hline Female & $3.91 \pm 0.84$ & & $3.91 \pm 0.88$ & & $3.97 \pm 0.84$ & & $3.84 \pm 0.87$ & \\
\hline \multicolumn{9}{|l|}{ Safety } \\
\hline Male & $3.54 \pm 1.17$ & $6.300(0.000)^{\star \star \star}$ & $3.66 \pm 1.15$ & $9.075(0.000)^{\star \star \star}$ & $3.62 \pm 1.17$ & $5.227(0.000)^{\star \star \star}$ & $3.51 \pm 1.16$ & $5.404(0.000)^{\star \star \star}$ \\
\hline Female & $3.28 \pm 1.03$ & & $3.27 \pm 1.03$ & & $3.38 \pm 1.02$ & & $3.26 \pm 1.02$ & \\
\hline \multicolumn{9}{|c|}{ Objective knowledge } \\
\hline Male & $0.46 \pm 0.25$ & $5.988(0.000)^{\star \star \star}$ & $0.63 \pm 0.24$ & $4.135(0.000)^{\star \star \star}$ & $0.47 \pm 0.24$ & $9.496(0.000)^{\star \star \star}$ & $0.62 \pm 0.22$ & $6.194(0.000)^{\star \star \star}$ \\
\hline Female & $0.40 \pm 0.23$ & & $0.60 \pm 0.24$ & & $0.38 \pm 0.23$ & & $0.56 \pm 0.23$ & \\
\hline \multicolumn{9}{|l|}{ Attitude } \\
\hline Male & $2.05 \pm 1.42$ & $7.525(0.000)^{\star \star \star}$ & $3.25 \pm 1.74$ & $6.406(0.000)^{\star \star \star}$ & $2.10 \pm 1.37$ & $7.989(0.000)^{\star \star \star}$ & $3.07 \pm 1.69$ & $3.474(0.001)^{\star \star}$ \\
\hline Female & $1.66 \pm 1.21$ & & $2.83 \pm 1.62$ & & $1.65 \pm 1.25$ & & $2.83 \pm 1.63$ & \\
\hline
\end{tabular}

The ratio of female to male students is not significant, with 2,396 (48.56\%) female students and 2,538 (51.43\%) male students.

$\mathrm{M}$, mean; SD, standard deviation.

${ }^{* *} p<0.05,{ }^{* \star *} p<0.001$

Table 4. Mock Voting on Nuclear Power Plant Construction

\begin{tabular}{|c|c|c|c|c|}
\hline \multirow{2}{*}{ Division } & \multicolumn{2}{|c|}{2016} & \multicolumn{2}{|c|}{2017} \\
\hline & Before education & After education & Before education & After education \\
\hline \multicolumn{5}{|c|}{ Opinion on nuclear power plant construction in South Korea } \\
\hline For & 1,094 (53.4) & $1,460(68.6)$ & $833(51.3)$ & $1,141(66.0)$ \\
\hline Against & $954(46.6)$ & $669(31.4)$ & $792(48.7)$ & $589(34.0)$ \\
\hline Total & $2,048(100)$ & $2,129(100)$ & $1,625(100)$ & $1,730(100)$ \\
\hline \multicolumn{5}{|c|}{ Reasons for opposition } \\
\hline Dangerous & $841(84.1)$ & $513(70.9)$ & $730(80.0)$ & $498(75.6)$ \\
\hline Inappropriate & $100(9.06)$ & $80(11.0)$ & $71(7.8)$ & $67(10.2)$ \\
\hline Not preferring & $70(6.3)$ & $51(7.0)$ & $48(5.3)$ & $37(5.6)$ \\
\hline Others & $53(4.8)$ & $39(5.4)$ & $39(4.3)$ & $20(3.0)$ \\
\hline Unnecessary & $39(3.5)$ & $41(5.6)$ & $25(2.7)$ & $37(5.6)$ \\
\hline Total & $1,103(100)$ & 724 (100) & $913(100)$ & $659(100)$ \\
\hline
\end{tabular}

Values are presented as number of students with percentage in parentheses.

A mock voting was performed regarding nuclear power plant construction in South Korea before and after education on the topic. The results were based on decisions by the students using their own discretion, and the students who voted against the construction provided the reasons for the opposition. The categories included "Dangerous", "Inappropriate to South Korea", "Not preferring nuclear power generation", "Unnecessary", and "Others".

\section{Mock Voting on Nuclear Power Plant Construction}

In 2016 and 2017, the number of students who agreed to build a nuclear power plant in South Korea was higher after educational influence than before the education influence. The proportion of students opposed to the construction of nuclear power plants were mostly due to the reason of it being "dangerous" before and after education in 2016 was $84.1 \%$ and $70.9 \%$ as well as before and after education in 2017 was $\mathbf{8 0 . 0 \%}$ and $75.6 \%$. Following educational awareness, the percentage of voters opposed due to it being "dangerous" became lower than that before education awareness. The rea- son "unnecessary" scored as low as $6 \%$, which suggests that nuclear power generation policy prioritizes risk as a necessity. That suggestion should be interpreted as providing information on the necessity for nuclear power does not have a high educational effect on the nuclear power expert group. Rather, it is necessary to treat safety issues more seriously (Table 4).

\section{Factors Affecting Safety Awareness on Nuclear Power Generation and Radiation}

To find the main variables affecting the risk (safety) aware- 
Table 5. Factors Affecting Safety Awareness on Nuclear Power Generation and Radiation

\begin{tabular}{|c|c|c|c|c|c|c|}
\hline \multicolumn{3}{|c|}{ Division } & \multirow{2}{*}{$\frac{B}{-0.138}$} & \multirow{2}{*}{$\begin{array}{c}\text { Standard error } \\
0.032\end{array}$} & \multirow{2}{*}{$\begin{array}{l}\beta \\
-\end{array}$} & \multirow{2}{*}{$\frac{t}{-4.238}$} \\
\hline 2016 & Before education & (Constant) & & & & \\
\hline & & Necessity awareness & 0.002 & 0.009 & 0.004 & 0.195 \\
\hline & & Safety awareness & 0.081 & 0.007 & 0.239 & $11.471^{\star \star \star}$ \\
\hline & & Nuclear safety knowledge & -0.001 & 0.033 & -0.001 & -0.024 \\
\hline & & Medical radiation knowledge & -0.122 & 0.028 & -0.106 & $-4.339^{\star \star \star}$ \\
\hline & & Irradiated food knowledge & 0.045 & 0.028 & 0.035 & 1.605 \\
\hline & & Safety knowledge & 0.046 & 0.018 & 0.056 & $2.514^{\star}$ \\
\hline & & Irradiated food attitude & 0.187 & 0.019 & 0.193 & $9.972^{\star \star \star}$ \\
\hline & & Medical radiation attitude & 0.103 & 0.018 & 0.118 & $5.876^{\star \star \star}$ \\
\hline & & & \multicolumn{4}{|c|}{$F=55.918^{\star \star \star}, R^{2}=0.150$} \\
\hline & After education & (Constant) & -0.405 & 0.037 & - & -10.871 \\
\hline & & Necessity awareness & -0.010 & 0.011 & -0.018 & -0.847 \\
\hline & & Safety awareness & 0.186 & 0.009 & 0.437 & $21.109^{\star \star \star}$ \\
\hline & & Nuclear safety knowledge & 0.008 & 0.042 & 0.004 & 0.196 \\
\hline & & Medical radiation knowledge & -0.032 & 0.031 & -0.020 & -1.039 \\
\hline & & Irradiated food knowledge & 0.092 & 0.028 & 0.068 & $3.246^{\star \star}$ \\
\hline & & Safety knowledge & 0.058 & 0.023 & 0.050 & $2.535^{\star}$ \\
\hline & & Irradiated food attitude & 0.135 & 0.018 & 0.140 & $7.452^{\star \star \star}$ \\
\hline & & Medical radiation attitude & 0.201 & 0.024 & 0.159 & $8.521^{\star \star \star}$ \\
\hline & & & \multicolumn{4}{|c|}{$F=192.156^{\star \star \star}, R^{2}=0.376$} \\
\hline \multirow[t]{18}{*}{2017} & Before education & (Constant) & 3.129 & 0.055 & - & 56.626 \\
\hline & & Nuclear safety knowledge & 0.008 & 0.021 & 0.009 & 0.363 \\
\hline & & Medical radiation knowledge & -0.011 & 0.018 & -0.016 & -0.621 \\
\hline & & Irradiated food knowledge & 0.024 & 0.018 & 0.031 & 1.335 \\
\hline & & Safety knowledge & -0.010 & 0.030 & -0.008 & -0.350 \\
\hline & & Irradiated food attitude & 0.120 & 0.030 & 0.085 & $4.010^{\star \star}$ \\
\hline & & Medical radiation attitude & 0.082 & 0.028 & 0.065 & $2.982^{\star}$ \\
\hline & & Nuclear safety attitude & 0.401 & 0.030 & 0.280 & $13.455^{\star \star}$ \\
\hline & & & \multicolumn{4}{|c|}{$F=37.884^{\star \star}, R^{2}=0.108$} \\
\hline & \multirow[t]{9}{*}{ After education } & (Constant) & 2.501 & 0.070 & - & 35.571 \\
\hline & & Nuclear safety knowledge & 0.056 & 0.021 & 0.057 & $2.633^{\star \star}$ \\
\hline & & Medical radiation knowledge & -0.051 & 0.016 & -0.066 & $-3.213^{\star \star}$ \\
\hline & & Irradiated food knowledge & 0.042 & 0.015 & 0.065 & $2.840^{\star *}$ \\
\hline & & Safety knowledge & -0.001 & 0.028 & -0.001 & -0.028 \\
\hline & & Irradiated food attitude & 0.218 & 0.023 & 0.192 & $9.286^{\star \star}$ \\
\hline & & Medical radiation attitude & 0.005 & 0.030 & 0.004 & 0.178 \\
\hline & & Nuclear safety attitude & 0.495 & 0.023 & 0.418 & $21.130^{\star \star}$ \\
\hline & & & \multicolumn{4}{|c|}{$F=79.284^{\star \star}, R^{2}=0.201$} \\
\hline
\end{tabular}

Knowledge within each field (nuclear energy, medical radiation, and irradiated food), is judged by the level of objective knowledge, meaning that an individual has a high level of knowledge in this respect. Necessity and safety awareness mean that nuclear power generation is necessary or safe. Attitude relates to the choice of using nuclear power generation or radiation. Safety attitude had the greatest influence on safety awareness. This is because it recognizes that it is not safe to make the choice to do something which could be potentially harmful. In the end, a program is needed to induce attitudes rather than knowledge in the educational design utilized by students.

${ }^{*} p<0.05,{ }^{* *} p<0.01,{ }^{* *} p<0.001$

ness in relation to nuclear power generation, which is the main reason for future generations' opposition to nuclear power, a multiple linear regression analysis was performed by setting safety awareness as a dependent variable, and knowledge on radiation field use (nuclear power generation, medical radiation, and irradiated food), food choice attitude, and medical radiation choice attitude, as independent variables (Table 5). Consequently, nuclear safety attitude was the most influential factor in 2017, unlike that in 2016. Even after education on this topic, nuclear safety attitude was the most influential, which is understandable as security was the main reason behind the opposition to nuclear power. To change attitudes, it is often necessary to consider that public awareness on the topic of science and technology is made in an emotion-based empirical framework [27]. Finucane et al. [28] also showed that emotions play a crucial role in the type of 
judgment regarding risks and benefits because various factors, such as emotions, experiences, socio-cultural environment, and values, are more important in human judgment [29-31]. According to Slovic [32], experts perform an assessment with a revealed preference that determines risk acceptance through a technological approach, and the public performs an assessment with an expressed preference that determines risk acceptance through individual awareness to construct the risk awareness. Therefore, education should be designed not only in a way to provide objective knowledge but also to consider cultural changes based on emotion. It should be considered that the public awareness of science and technology occurs in an emotion-based empirical framework rather than a knowledge-based one [33].

\section{Conclusion}

In the face of the nuclear communication problem, the type and method of conveying the message is the most basic consideration for effective and efficient communication policies $[34,35]$. Nevertheless, it is no exaggeration to say that communications have failed in South Korea because to date, unilateral education has been provided on nuclear power communication targeting the general public. While some studies on nuclear power have examined the close correlation between the degree of knowledge and the awareness of nuclear power [36], behavioral intentions of human beings leads to behavior [37], and behavioral intentions are strongly linked to behavior [33], necessitating the understanding of public intentions on changes related to nuclear power reduction policies. In the theory of reasoned action, Ajzen [38] argues that humans use their own information as much as possible before an action by considering the benefits and disadvantages from the consequences of that action. Typically, the greater the benefits are from nuclear power, the higher is the awareness (or acceptability) level regarding nuclear power [39, 40]. Because various factors such as emotion, experience, socio-cultural environment, and general values play a more important role in human judgment [31, 41], it is necessary to help people make rational decisions by providing varied forms of information. Basically, the general public's attitude change on nuclear power could vary within each country [42, 43], and public attitudes on science vary according to the level of knowledge involved. As knowledge accumulates, rational decisions are better facilitated [44]. Thus, it is necessary to provide balanced information on nu- clear power in any form of available education. Because individual awareness determines individual risk acceptance $[45,46]$, an educational approach based on emotion is required henceforth. Furthermore, because the safety awareness of future generations will have a significant influence on the policy decisions surrounding nuclear power generation, education needs to be designed to match safety variables suitable to a student's level. It is well known that more consideration and concentration on learners leads to efficient education [47]. Thus, the question of safety attitude, which is a view on safety issues, is emphasized as an important indicator of safety culture $[48,49]$. The instituted procedures incorporate safety regulations and procedures as the central conceptual elements of the safety atmosphere, and such instituted procedures should be considered as an organizational variable that has a decisive influence on the outcome of individual safety behavior [49]. Dealing with regulations on safety and safety management based on emotions will produce educational effects which facilitate judicious decisions regarding nuclear power generation and radiation safety by primary, middle, and high school students in South Korea.

\section{Conflict of Interest}

No potential conflict of interest relevant to this article was reported.

\section{Acknowledgements}

This work was granted financial resource from the Nuclear Safety and Security Commission (NSSC), Republic of Korea.

\section{Author Contribution}

Conceptualization: Han EO. Data curation: Han EO. Formal analysis: Han EO. Funding acquisition: Choi YS. Methodology: Han EO. Project administration: Choi YS. Visualization: Han EO. Writing - original draft: Han EO. Writing - review \& editing: Kim JM. Investigation: Choi YS, Han EO. Resources: Choi YS. Software: Choi YS. Supervision: Choi YS. Validation: Kim JM.

\section{References}

1. Lee TJ, Ki BJ, Kim IS. A national survey of the policy customers' 
perceptions and beliefs of nuclear energy issues and agenda. Korean J Advert. 2015;26:299-323.

2. Yi J, Lee J, Seok D. Identification of dimensions in organizational safety climate and relationship with safety behavior. Korean J Ind Organ Psychol. 2011;24:627-650.

3. Bird DK, Haynes K, van den Honert R, McAneney J, Poortinga W. Nuclear power in Australia: a comparative analysis of public opinion regarding climate change and the Fukushima disaster. Energy Policy. 2014;65:644-653.

4. Prati G, Zani B. The effect of the Fukushima nuclear accident on risk perception, antinuclear behavioral intentions, attitude, trust, environmental beliefs, and values. Environ Behav. 2013;45:782798.

5. Visschers VH, Siegrist M. Fair play in energy policy decisions: procedural fairness, outcome fairness and acceptance of the decision to rebuild nuclear power plants. Energy Policy. 2012;46: 292-300.

6. Yamamura E. Experience of technological and natural disasters and their impact on the perceived risk of nuclear accidents after the Fukushima nuclear disaster in Japan 2011: a cross-country analysis. J Socio Econ. 2012;41:360-363.

7. Greenberg M, Lowrie K, Burger J, Powers C, Gochfeld M, Mayer H. The ultimate LULU? Public reaction to new nuclear activities at major weapons sites. J Am Plann Assoc. 2007;73:346-351.

8. Lee HJ, Park ST. Comparison of perception differences about nuclear energy in 4 East Asian Country students: aiming at $10^{\text {th }}$ grade students who participated in scientific camps, from four East Asian countries: Korea, Japan, Taiwan, and Singapore. J Korean Assoc Sci Educ. 2012;32:775-788.

9. Slovic P. Perceived risk, trust, and democracy. Risk Anal. 1993; 13:675-682.

10. Han DS, Bae JH, Kim HI, Ju JH. Nuclear policy, government reliability and communication strategy. Seoul, Korea: Ministry of Science and Technology; 2004.

11. Lee JR, Lim SH, Shin TS. The tsunami-devastated Fukushima nuclear power plant accident and media discourse. Speech Commun. 2011;16:188-213.

12. Nemoto M, Park YH. Improving safety against nuclear power for elementary, middle and high school student: focused on radiation education in Japan. Crisisonomy. 2015:11:93-113.

13. Sadler TD. Informal reasoning regarding socioscientific issues: a critical review of research. J Res Sci Teach. 2004;41:513-536.

14. Zeidler DL, Keefer, M. The role of moral reasoning and the status of socioscientific issues in science education. In: Zeidler DL, editor. The role of moral reasoning on socioscientific issues and discourse in science education. Dordrecht, Germany: Springer, 2003. p. 7-38.

15. Zeidler DL, Sadler TD, Simmons ML, Howes EV. Beyond STS: a research-based framework for socioscientific issues education. Sci Educ. 2005;89:357-377.
16. Jang J, Mun J, Ryu HS, Choi K, Joseph K, Kim SW. Korean middle school students' perceptions as global citizens of socioscientific issues. J Korean Assoc Sci Educ. 2012;32:1124-1138.

17. Lee SK, Choi YS, Han EO. Curriculum development for nuclear power and radiation education in elementary, middle, and high schools. J Radiat Prot Res. 2014;39:187-198.

18. Han EO, Kim JR, Choi YS, James L. Development of nuclear energy and radiation textbooks for elementary, middle, and high school students. J Radiat Prot Res. 2015;40:132-146.

19. Okada T, Watanabe H, Sonobe T. Practice of radiation education class utilizing local educational resources (2): practice of radiation education in science class of junior high school attached to Fukushima University. Bull Cent Res Dev Educ Fukushima Univ. 2013;15:17-24.

20. Girondi AJ. A discriminant analysis of attitudes related to the nuclear power controversy. J Environ Educ. 1983;14:2-6.

21. Eiser JR, van der Pligt J. Nuclear energy, risk perception and attitudes. In: Attitudes and decisions. London, UK: Psychology Press; 1988. p. 150-174.

22. Cho KY, Moon JH. Investigation of perception of nuclear power by the local residents adjacent to nuclear installations. J Nucl Fuel Cycle Waste Technol. 2011;9:181-189.

23. Moon KS, Chang YC. An empirical analysis on safety climate constructs within Korean companies. Q J Labor Policy. 2014;14:131154.

24. Lidskog R. Scientised citizens and democratised science: re-assessing the expert-lay divide. J Risk Res. 2008;11:69-86.

25. McComas KA. Defining moments in risk communication research: 1996-2005. J Health Commun. 2006;11:75-91.

26. Sjoberg L. Risk perception by the public and by experts: a dilemma in risk management. Hum Ecol Rev. 1999;6:1-9.

27. Krimsky S. The role of theory in risk studies. In: Krimsky S, Golding D, editors. Social theories of risk. Westport, CT: Praeger Publishers; 1992. p. 3-23.

28. Finucane ML, Alhakami A, Slovic P, Johnson SM. The affect heuristic in judgments of risks and benefits. J Behav Decis Mak. 2000; 13:1-17.

29. Honkanen P, Verplanken B. Understanding attitudes towards genetically modified food: the role of values and attitude strength. J Consum Policy. 2004;27:401-420.

30. Bem D. The concept of risk in the study of human behavior. In: Dowie J, Lefrere P, editors. Risk and chance: selected readings. Keynes, England: The Open University Press; 1980. p. 1-15.

31. Harris AJ, Hahn U. Unrealistic optimism about future life events: a cautionary note. Psychol Rev. 2011;118:135-154.

32. Slovic P. Perception of risk: reflections on the psychometric paradigm. In: Golding D, Krimsky S, editors. Theories of risk. New York, NY: Praeger Publisher; 1990. p. 117-152.

33. Nutbeam D, Harris E, Wise W. Theory in a nutshell: a practical guide to health promotion theories. 2nd ed. Sydney, Australia: 
McGraw-Hill; 2004.

34. Lee YN, Kim YS, Lee JY. A study on audience-centered government policy promotion and diffusion model: With focus on properties of the policy and communication characteristics of the organization. Korean J Advert. 2013;24:39-95.

35. Gelb BD, Meade JA. Advertising to communicate public policy: applying lessons from Federal Tax Law. J Curr Issues Res Advert. 2005;27:99-105.

36. Sjoberg L, Drottz-Sjoberg BM. Knowledge and risk perception among nuclear power plant employees. Risk Anal. 1991;11:607618.

37. Ajzen I, Fishbein M, Heilbroner RL. Understanding attitudes and predicting social behavior. Englewood Cliffs, NJ: Prentice-Hall; 1980.

38. Ajzen I. From intentions to actions: a theory of planned behavior. In: Kuhl J, Beckmann J, editors. Action control. Heidelberg: Springer; 1985. p. 11-39.

39. Ho JC, Kao SF, Wang JD, Su CT, Lee CT, Chen RY, et al. Risk perception, trust, and factors related to a planned new nuclear power plant in Taiwan after the 2011 Fukushima disaster. Journal of Radiological Protection. 2013;33:773-789.

40. De Groot JI, Steg L, Poortinga W. Values, perceived risks and ben- efits, and acceptability of nuclear energy. Risk Anal. 2013;33: 307-317.

41. Reed SK. Cognition: theories and applications. Belmont, CA: Wadsworth; 2010.

42. Ramana MV. Nuclear policy responses to Fukushima: exit, voice, and loyalty. Bull At Sci. 2013;69:66-76.

43. Drottz-Sjoberg BM, Sjoberg L. Risk perception and worries after the Chernobyl accident. J Environ Psychol. 1990;10:135-149.

44. Scheufele DA, Lewenstein BV. The public and nanotechnology: how citizens make sense of emerging technologies. J Nanopart Res. 2005;7:659-667.

45. Slovic P. Perception of risk. Science 1987;236:280-285.

46. Fischhoff B, Slovic P, Lichtenstein S, Read S, Combs B. How safe is safe enough? A psychometric study of attitudes towards technological risks and benefits. Policy Sci. 1978;9:127-152.

47. Cox S, Cox T. The structure of employee attitudes to safety: a European example. Work Stress. 1991;5:93-106.

48. Cox SJ, Cheyne AJ. Assessing safety culture in offshore environments. Saf Sci. 2000;34:111-129.

49. Zohar D. A group-level model of safety climate: testing the effect of group climate on microaccidents in manufacturing jobs. J Appl Psychol. 2000;85:587-596. 